\title{
ИСПОЛЬЗОВАНИЕ БИОСУБСТРАТОВ ОРГАНИЗМА ЧЕЛОВЕКА В КАЧЕСТВЕ ОБЪЕКТОВ ЭКОЛОГИЧЕСКОГО МОНИТОРИНГА ПОЛИМЕТАЛЛИЧЕСКОГО ЗАГРЯЗНЕНИЯ НА УРБАНИЗИРОВАННОЙ ТЕРРИТОРИИ 1
}

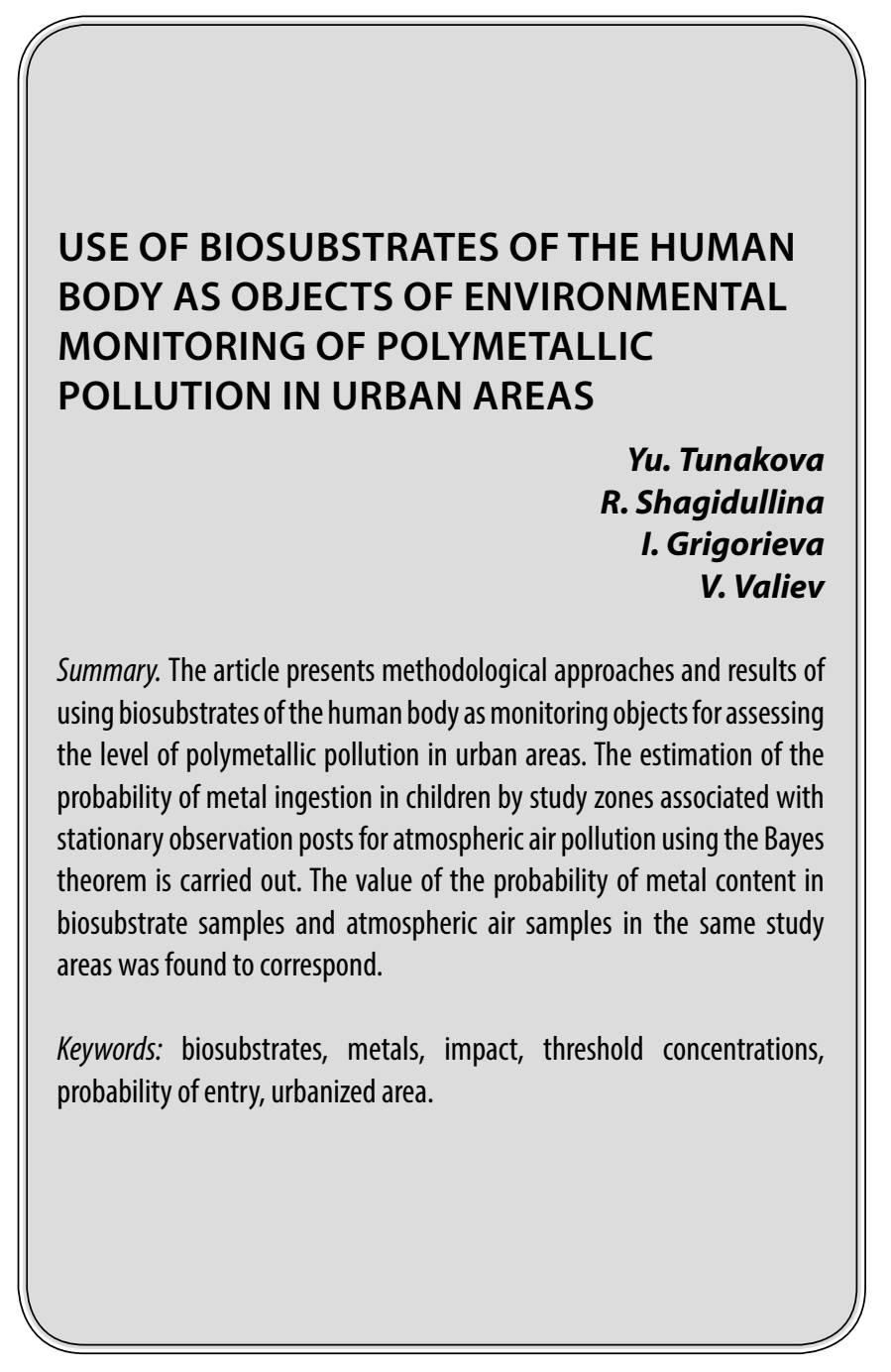

\section{Ввемение}

$\mathbf{H}$ а урбанизированной территории важнейшим биообъектом, отклик которого служит критерием при оценке уровня загрязнения территории и основным защищаемым объектом является человек, поэ-
Тунакова Юлия Алексеевна

Д.х.н., профессор, ФГБОУ ВО «Казанский начиональный исследовательский технический университет им. А. Н. Туполева-КАИ»

juliaprof@mail.ru

Шагидуллина Раиса Абдулловна

Д.х.н., начальник управления, Министерство экологии и природных ресурсов Республики Татарстан raisa.shagidullina@tatar.ru

Григорьева Ирина Геннадьевна Старший преподаватель, ФГБОУ ВО «Казанский национальный исследовательский технический университет им. А. Н. Туполева-КАИ» grig406@yandex.ru Валиев Всеволод Сергеевич

С.н.с., Институт проблем экологии и недропользования АН РT, РФ podrost@mail.ru

Аннотация. В статье приводятся методические подходы и результаты использования биосубстратов организма человека как мониторинговых объектов для оценки уровня полиметаллического загрязнения на урбанизированной территории. Проведена оценка вероятности поступления металлов в организм детей по зонам исследования, приуроченным к стационарным постам наблюдений за загрязнением атмосферного воздуха, с использованием теоремы Байеса. Установлено соответствие значений вероятности содержания металлов в пробах биосубстратов и пробах атмосферного воздуха в одних и тех же зонах исследования.

Ключевые слова: биосубстраты, металлы, воздействие, пороговые концентрации, вероятность поступления, урбанизированная территория. тому учет реакций организма человека необходим при проведении экологического мониторинга. В последние годы содержание металлов в организме человека рассматривается в неотъемлемой связи с региональными биогеохимическими особенностями мест проживания обследуемых [1-4]. 
Работы по изучению мониторинговой роли биосубстратов организма человека [5-6] позволяют рекомендовать их для оценки условий формирования техногенных полиметаллических аномалий локального характера на территории с высоким уровнем антропогенной нагрузки. Установив влияние аэрогенных потоков металлов на изменение состава биосубстратов, можно не только дать интегральную оценку воздействия на человека факторов окружающей среды, но и использовать биосубстраты организма в качестве мониторинговых показателей для характеристики распределения аэрогенного привноса [7-9]. К настоящему времени установлено, что концентрации металлов в организмах прямо пропорциональны содержанию их в среде обитания с учетом растворимости соединений, но исследование содержания металлов в биосубстратах организма человека очень редко применяется при проведении мониторинговых обследований на урбанизированной территории [10-11].

Выбор того или иного биосубстрата в качестве объекта диагностики часто обусловливается аналитическими возможностями лаборатории и простотой отбора того или иного биологического образца. Однако, помимо абсолютных величин концентраций металлов во внешней среде важна длительность их воздействия. Примерно в одно и тоже время на территории Китая [13], Португалии [14], Италии [15] были проведены масштабные исследования накопления металлов $\mathrm{As}, \mathrm{Cd}, \mathrm{Cr}, \mathrm{Mn}$ и $\mathrm{Pb}$, в диагностических биосубстратах различных возрастных групп населения, проживающих в районах добычи руд, в промышленных зонах с высоким уровнем полиметаллического воздействия. Было показано значительное, статистически значимое увеличение концентраций металлов во всех диагностических биосубстратах (волосы, ногти, кровь, моча) по сравнению с контрольной группой. Отмечены достоверно более высокие уровни содержания металлов в волосах детей по сравнению с другими возрастными группами, что позволяет использовать результаты определения металлов в волосах для зонирования территории при экологическом мониторинге полиметаллического загрязнения. Волосы считаются диагностическим биосубстратом, обобщающим многосредовое воздействие и учитывающим все пути поступления металлов в организм, в том числе и в условиях многолетнего аэрогенного воздействия [11-15].

Поэтому в качестве мониторингового показателя для исследования территории с высоким уровнем полиметаллического загрязнения нами был выбран биосубстрат - волосы детского населения. Выбор для исследования волос детей обусловлен большей их чувствительностью к факторам внешней среды, а также отсутствием вредных привычек, профессиональных и возрастных заболеваний, которые могут исказить ре- зультаты исследования. Изучение биосубстратов детей позволяет проводить исследования с территориальной дифференциацией, ввиду локального местонахождения детей в течение длительного периода времени. Особое значение имеют исследования, направленные на определение фоновых концентраций металлов в волосах, обобщающие влияние внешних факторов до некоторого его взвешенного уровня, превышение которого является маркером длительного интегрального неблагоприятного антропогенного воздействия в пределах конкретного участка территории города $[1,4.7,11]$.

\section{Материалы и методы исследования}

В качестве территории исследования нами выбран город Нижнекамск, характеризующийся высоким уровнем аэрогенного поступления металлов в приземный слой атмосферного воздуха. Город Нижнекамск неоднократно попадал в список городов и территорий РФ с высоким уровнем загрязнения атмосферного воздуха [16].

Репрезентативную группу обследуемых в рамках специального мониторингового исследования составили 70 детей от 6 до 10 лет $(9,16 \pm 0,13$ лет), проживающих на территории города Нижнекамска. Места жительства детей были приурочены к 5 точкам размещения стационарных постов наблюдений Министерства экологии и природных ресурсов РТ: АСКЗА- 11 (ул. Гагарина, 32а), АСКЗА-12 (ул. Ямьле, 20), АСКЗА-13 - ул. Ахтубинская, 4Б, АСКЗА-14 (Нижнекамский м.р., с. Большое Афанасово, ул. Молодежная, 1), АСКЗА-15 (ул. Южная, 7). Оценивалось содержание в волосах детей 9 металлов, поступающих с выбросами в атмосферный воздух города Нижнекамск: $\mathrm{Zn}, \mathrm{Cd}, \mathrm{Cu}, \mathrm{Mn}, \mathrm{Ni}, \mathrm{Pb}, \mathrm{Cr}, \mathrm{Fe}, \mathrm{Sr}$.

Образцы волос детей взвешивались на аналитических весах с точностью до 0,01 мг. Предварительно смоченные $\mathrm{HNO}_{3}$ конц. каждая навески пробы, сжигалась в муфельной печи в фарфоровом тигле при постепенном (в течение 1 часа) подъеме температуры до $450{ }^{\circ} \mathrm{C}$ (метод «сухого озоления»). Полученная зола растворялась в 15 мл 1 н. азотной кислоты (х.ч.), раствор отфильтровывался через беззольный фильтр («синяя лента»). Для приготовления растворов использовалась бидистиллированная вода и стеклянная посуда (ГОСТ 1770-74).

Для мониторинговых исследований основной задачей которых является анализ большого количества образцов с достаточной массой пробы, целесообразно применение рутинных методов анализа. С этой целью в качестве аналитического метода определения металлов в волосах нами использовался метод атомно-абсорбционной спектрометрии (ААC), показавший себя как точный, воспроизводимый, отличающихся высокой избирательностью и быстротой исполнения, с упрощен- 


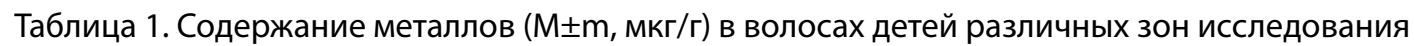

\begin{tabular}{|c|c|c|c|c|c|}
\hline \multirow{2}{*}{ Металл } & \multicolumn{5}{|c|}{ Содержание металлов (M $\pm m$, мкг/г), зоны исследования } \\
\hline & ACK3A-12 & ACK3A- 14 & ACK3A- 13 & ACK3A- 15 & ACK3A- 11 \\
\hline $\mathrm{Zn}$ & $92,4 \pm 7,8$ & $110,7 \pm 7,1$ & $114,5 \pm 7,1$ & $104,5 \pm 7,5$ & $123,5 \pm 12,7$ \\
\hline $\mathrm{Cd}$ & $0,64 \pm 0,11$ & $0,61 \pm 0,14$ & $0,72 \pm 0,16$ & $0,71 \pm 0,13$ & $0,87 \pm 0,14$ \\
\hline $\mathrm{Cu}$ & $9,23 \pm 1,21$ & $10,6 \pm 0,89$ & $11,4 \pm 0,92$ & $11,3 \pm 1,25$ & $11,3 \pm 0,99$ \\
\hline $\mathrm{Mn}$ & $1,046 \pm 0,28$ & $1,005 \pm 0,16$ & $1,087 \pm 0,06$ & $1,12 \pm 0,18$ & $0,97 \pm 0,12$ \\
\hline $\mathrm{Ni}$ & $0,82 \pm 0,17$ & $1,24 \pm 0,27$ & $1,42 \pm 0,26$ & $1,13 \pm 0,16$ & $1,25 \pm 0,22$ \\
\hline $\mathrm{Pb}$ & $4,27 \pm 0,3$ & $10,47 \pm 1,72$ & $7,69 \pm 1,07$ & $8,35 \pm 0,81$ & $6,6 \pm 1,79$ \\
\hline $\mathrm{Cr}$ & $0,418 \pm 0,11$ & $1,43 \pm 0,35$ & $0,87 \pm 0,09$ & $1,026 \pm 0,15$ & $1,32 \pm 0,16$ \\
\hline $\mathrm{Fe}$ & $22,2 \pm 4,3$ & $22,6 \pm 1,52$ & $20,6 \pm 1,79$ & $17,7 \pm 1,12$ & $28,2 \pm 3,79$ \\
\hline $\mathrm{Sr}$ & $11,9 \pm 3,68$ & $6,85 \pm 1,006$ & $9,65 \pm 1,34$ & $6,55 \pm 0,81$ & $8,61 \pm 1,14$ \\
\hline
\end{tabular}

ной пробоподготовкой анализа содержания металлов в волосах. Определение металлов в отобранных биосубстратов проводилось на приборе AAnalyst 400. Исследования проводились в аналитической лаборатории Института проблем экологии и недропользования Академии наук Республики Татарстан на поверенном оборудовании с использованием рекомендованных методик выполнения измерений.

\section{Обсужление результатов}

Результаты экспериментальных исследований представлены в табл. 1. При сопоставлении средних значений содержания различных металлов по участкам исследования статистически значимо (уровень значимости p<0,05) выделяются: по Cd - зона АСК3А-11 (достоверно отличаются от зон АСКЗА-12 и АСК3А-14); по Рb - зоны АСКЗА-14 и АСКЗА-15 (достоверно отличаются от АСК3А-12); по Cr - зоны АСКЗА-11 и АСКЗА-14 (достоверно отличаются от зоны АСКЗА-12). По остальным металлам статистически значимых различий не отмечено, хотя и присутствует значительный разброс средних значений.

Если в среднестатистическом выражении поступление металлов по водно-пищевому пути в организм детей-школьников в пределах единой городской среды можно принять за величину постоянную, то содержание металлов в атмосферном воздухе может варьировать в значительных пределах в зависимости от особенностей рассеивания примесей на конкретном участке территории.

Статистический анализ данных по содержанию различных металлов в волосах обследованных детей позволил также рассчитать фоновые значения концентраций, величины которых соответствуют нижнему квартилю ранжированного ряда всех значений концентраций того или иного металла (мкг/г): Zn-93,6; Cd-0,4; Cu-8,86; Mn-0,8; $\mathrm{Ni}-0,7 ; \mathrm{Pb}-4,1$; Cr-0,6; Fe-16,0; Sr-5,7, которые можно использовать в качестве пороговых значений.

На основании рассчитанных концентраций нами проводилась оценка риска полиметаллического воздействия на организм детей, проживающих в различных зонах исследования. Оптимальным способом масштабирующим разноразмерные переменные является отнесение каждого фактора риска к его пороговому значению, что показывает проявление события, вероятность которого в случае целого ряда событий описывается теоремой Байеса, учитывающей как априорные, так и апостериорные вероятности [17].

Для оценки фактов превышения конкретными значениями фонового показателя было введено соответствующее отношение фактических концентраций к фоновым: $C_{\text {факт }} / C_{\text {фон }}$ которое называют коэффициентом опасности (HQ). HQ является адаптированным вариантом общепринятого аналогичного показателя коэффициента опасности, рассчитываемого как отношение AC / $\mathrm{RfC}$, где AC - средняя концентрация, RfC - референтная (безопасная) концентрация.

В качестве интегрального группирующего признака рассчитывалась медиана всех коэффициентов опасности всех исследуемых металлов полученного ряда значений. Полученная в результате интегральная характеристика отражает вероятность превышения над фоном концентраций, как минимум, половины (50\%) анализируемых металлов.

Применение $\mathrm{HQ}$, а также медиан всех возможных значений $\mathrm{HQ}$ данного ряда наблюдений, позволяет приводить разные факторы к единой шкале, факт наступления события в которой задается 1. При таких условиях соразмерности, отдельные переменные можно рассматривать 
Таблица 2. Значения интегральных коэффициентов опасности и их Байесовы вероятности в различных зонах исследования

\begin{tabular}{|c|c|c|c|c|c|}
\hline \multirow{2}{*}{ Зоны } & \multicolumn{5}{|c|}{ Фиксированные значения НQ и их вероятности } \\
\hline & 0,5 & 1 & 1,5 & 2 & 2,5 \\
\hline ACK3A-11 & 0,200 & 0,210 & 0,267 & 0,700 & 1,00 \\
\hline ACK3A-12 & 0,071 & 0,048 & 0,000 & 0,000 & 0,00 \\
\hline ACK3A-13 & 0,143 & 0,161 & 0,200 & 0,000 & 0,00 \\
\hline ACK3A-14 & 0,157 & 0,145 & 0,133 & 0,000 & 0,00 \\
\hline ACK3A-15 & 0,143 & 0,129 & 0,067 & 0,000 & 0,00 \\
\hline
\end{tabular}

не только в качестве факторов риска (то есть, в качестве признаков, которые самостоятельно связаны с вероятностью возникновения негативного события настолько, что могут быть использованы для его прогнозирования), но и в качестве меры составных частей риска.

Дальнейшие оценки вероятностей относились именно к этому интегральному коэффициенту опасности, а в качестве расчетной методологии использовалась теорема Байеса, учитывающая вероятность рискового события в конкретной точке пространства относительно информации о том, насколько часто это событие происходило на всей территории.

Вероятность признака при конкретных условиях равна отношению произведения доли признака при данных условиях с долью относительного числа наблюдений в этих условиях к сумме всех таких произведений при всех возможных условиях. В результате проведенных расчетов получены следующие вероятностные характеристики распределения интегрального $\mathrm{HQ}$ по содержанию металлов в волосах детей, проживающих в зонах охвата различных АСКЗА г. Нижнекамска (табл. 2).

Анализ полученных результатов позволяет выделить участки, расположенные в зоне АСКЗА 11, как имеющие наибольшую вероятность высоких концентраций металлов в волосах детей. Если рассматривать вероятность превышения содержания в волосах условного металла в 1,5 раза, то нисходящий ряд значений выстраивается следующим образом: Гагарина $(0,267)>$ Ахтубинская $(0,2)>$ Молодежная $(0,133)>$ Южная $(0,067)>$ Ямьле $(0)$.

Особенно наглядно различие вероятностей наблюдается при их сравнении по зонам исследования в зависимости от различной степени превышения фона. Так, если сопоставлять распределение вероятностей в зависимости от заданного порога $\mathrm{HQ}$ по разным участкам исследования, то можно отметить, что начиная с 1,5-кратного превышения фона (коэффициента опасности >1,5) различия между участками начинают проявляться особенно четко. При этом, самая высокая вероятность боль- ших значений коэффициентов опасности содержания металлов в биосубстратах детей отмечена в районе ACK3A-11, а самая низкая - в районе АСКЗА-12. Оценочным смыслом рассчитанных вероятностей в данном случае является утверждение: «Интегральная вероятность одновременного превышения над фоном концентраций в волосах не менее половины из проанализированных металлов наиболее высока у детей проживающих в зоне ACK3А-11 (19\%), наименьшая вероятность такого события наблюдается среди детей, проживающих в районе ACK3A-12 (4,8\%)».

Использование теоремы Байеса является вероятностным методом оценки риска и обладает целым рядом преимуществ по сравнению с точечной детерминистической оценкой. Итоговая картина ситуации становится более четкой при сопоставлении значений вероятностей неблагоприятного события, полученных путем оценки загрязнения проб волос детей металлами и оценок загрязнения примесями проб атмосферного воздуха на одних и тех же участках исследования. При сопоставлении значения вероятностей, рассчитанных по участкам города, отмечается общая тенденция их изменчивости, что является дополнительным фактом, подтверждающим результаты проведенного анализа территориального распределения риска.

Максимальные и минимальные значения вероятности загрязнения как проб биосубстратов, так и проб атмосферного воздуха наблюдаются на одних и тех же участках исследования. Более того, изменчивости оценок загрязнения биосустратов и воздуха демонстрируют общую тенденцию, выстраиваясь в пропорционально сопоставимые возрастающие ряды (коэффициент корреляции $r=0,83, p=0,02)$ : ACK3A-12 < ACK3A-15 < ACK3A-14 < ACK3A-13 < ACK3A-11.

\section{Зак^ючение}

Показаны преимущества и возможности использования биосубстратов организма человека в качестве мониторингового объекта при проведении экологиче- 
ского мониторинга на урбанизированной территории. Получены фоновые концентрации металлов, определяемые в биосубстратах детей, характеризующие длительное поступление металлов на территории с высоким уровнем антропогенной нагрузки. Полученные фоновые концентрации предлагается использовать в качестве пороговых при разработке региональных нормативов содержания металлов в объектах окружающей среды на урбанизированной территории. Следует отметить, что вероятность накопления металлов в волосах детей является не только комплексным показателем, охватывающим все пути поступления металлов в организм, но и долгосрочным прогностическим критерием, обладающим значительной инерцией и агрегирующим информацию за длительный период времени. Полученный второй показатель - вероятность превышения пороговых концентраций примесей в воздухе, является краткосрочным прогностическим критерием, необходимым для оперативного прогнозирования. Соответствие полученных вероятностей свидетельствует о корректной оценке риска полиметаллического загрязнения на урбанизированной территории и адекватностью использования биосубстратов детей, как объектов мониторинга урбанизированной территории.

\section{ЛИТЕРАТУРА}

1. Скальный А. В. Химические элементы в физиологии и экологии человека. М.: Мир. Оникс 21 век, 2004. 216 с.

2. Авцын А.П., Жаворонков А. А., Риш М. А., Строчкова Л. С. Микроэлементозы человека: этиология, классификация, органопатология / АМН СССР.- М.: Медицинка, 1991, 496 с.

3. Новиков С. М. Методологическая схема обследования городского населения с многоуровневыми оценками экспозиции загрязнителями атмосферного воздуха / С. М. Новиков, Ю. А. Ревазова, В. М. Розенталь, И. М. Корсунская, И. Е. Зыкова, Л. В. Хрипач, Н. С. Скворцова, Т. Д. Князева // Гигиена и санитария. 2007. № 5. C. 65-67.

4. Рахманин Ю. А. Характеристика количественных значений региональных факторов экспозиции на исследуемых территориях / Ю. А. Рахманин, Т. А. Шашина, Т. Н. Унгуряну, С. М. Новиков, Н. С. Скворцова, А. В. Мацюк, Т. Б. Легостаева, Н. А. Антипанова // Гигиена и санитария. 2012. № 6. С. 30 -33.

5. Blaurock-Busch E., Amin 0. R., Dessoki H. H., Rabah T. Toxic metals and essential elements in hair and severity of symptoms among children with Autism // Maedica (Buchar). 2012. 7(1).P.38-48.

6. Carneiro M.F., Moresco M. B., Chagas G. R., Souza 0., Rhoden C. R. et al. Assessment of trace elements in scalp hair of a young urban population in Brazil. Biol. Trace Elem. Res. // 2011. 143. P. 815-824.

7. Ревич Б. А. Биомониторинг металлов в организме человека//Микроэлементы в медицине. 2005.№ 6 (4) С. 11-16.

8. Afridi H.I., Kazi T. G., Kazi N., Naeemullah, Arain S. S., Brahman K. D., Wadhwa S. K. Evaluation of chromium, cobalt and manganese in biological samples (scalp hair, blood, and urine) of Pakistani viral hepatitis (A-E) patients and controls // Clin Lab. 2013. 59(3-4). P. 247-256.

9. Chashchin V.P., Askarova Z. F., Larionova T. K. Chemical hair analysis in ore-dressing and processing plant workers // Med. Tr. Prom. Ekol. 2007. 10. P. 9-13.

10. Биомониторинг человека: факты и цифры. Копенгаген: Европейское региональное бюро В03, 2015 г.

11. WHO/IPCS. Environmental Health Criteria 155: Biomarkers and Risk Assessment: Concepts and Principles. World Health Organisation, International Programme on Chemical Safety, Geneva, 1993.

12. Определение химических соединений в биологических средах. Методы контроля. Химические факторы. Сборник методических указаний МУК4.1.7634.1.779-99. M. 2000. 152 c.

13. Qu C.S., Ma Z. W., Yang J. Human Exposure Pathways of Heavy Metals in a Lead-Zinc Mining Area, Jiangsu Province. China // PLoS One. 2012. 7(11).

14. Dongarrà G., Varrica D., Tamburo E., D'Andrea D. Trace elements in scalp hair of children living in differing environmental contexts in Sicily (Italy). Environ Toxicol. Pharmacol. 2012. 34(2):160-9.

15. Coelho P., Costa S., Silva S., Walter A. Metal(loid) levels in biological matrices from human populations exposed to mining contamination-Panasqueira Mine (Portugal) // J. Toxicol. Environ. Health. A. 2012.75 (13-15). P. 893-908.

16. Государственный доклад «0 состоянии и 06 охране окружающей среды Российской Федерации в 2018 году». Министерство природных ресурсов и экологии $Р Ф, 2019$.

17. Gigerenzer, Gerd and Hoffrage, Ulrich“How to improve Bayesian reasoning without instruction: Frequency formats." Psychological Review. 1995, 102: 684-704

( ) Тунакова Юлия Алексеевна ( juliaprof@mail.ru ), Шагидуллина Раиса Абдулловна ( raisa.shagidullina@tatar.ru ),

Григорьева Ирина Геннадьевна ( grig406@yandex.ru ), Валиев Всеволод Сергеевич ( podrost@mail.ru ).

Журнал «Современная наука: актуальные проблемы теории и практики» 